\title{
Knowledge-Based Strategic Management of Engineering and Basic Sciences for Achieving the New Technologies
}

\author{
Arezu Jahanshir \\ Department of Eng. Physic, Faculty of Buein Zahra Technical University, Qazvin, Iran
}

Email address:

jahanshir@bzte.ac.ir

To cite this article:

Arezu Jahanshir. Knowledge-Based Strategic Management of Engineering and Basic Sciences for Achieving the New Technologies. Journal of Investment and Management. Vol. 4, No. 1, 2015, pp. 34-37. doi: 10.11648/j.jim.20150401.15

\begin{abstract}
The knowledge-based management and strategy is involved in all human intellectual aspects and performance. The achievement of power, knowledge and innovation in new technologies directly depend on the appropriate strategic management and is along with the future study on the knowledge and sciences. Nowadays, it is impossible to have single access to modern technology and equipment because of the frequency and wide spread of information and increased different ranges of sciences. The governments have been successful in promoting their unique infrastructures of basic sciences and engineering until now according to their power and dominance in technology and industry; and prediction and empowerment of infrastructures for development in science and technology is dependent on the macro strategic management of government. Therefore, the international interactions and access to today's scientific information are essential to achieve the knowledgebased management of engineering and basic sciences. Therefore, the long-term objectives of knowledge production and access to new techniques are among the basics of innovation in the industry. To achieve a modern and industrial society, the appropriate management and foresight in producing and disseminating the knowledge have a major impact on the way of applying and guiding the efficient potential of human capital. The experts and policy makers in developed countries have deeply acknowledged that the potential for sustainable development in all scientific, social, economic, cultural and political aspects needs the knowledge-based strategic management. According to the way of dissemination and progress of sciences in developed countries, we find out that the specific strategies have been developed for sustainable development in technology and innovation. The authors in this paper have conducted an overview of new knowledge-based management structures and selected the appropriate strategic policies in sustainable science and technology development of developing and semi-industrial countries.
\end{abstract}

Keywords: Hi-Tech Management, Modern Technologies, Innovation, Human Capital

\section{Introduction}

The continuous knowledge of scientific shortages and theorization about solving them is the factor for development of innovation and idea making in the field of engineering and basic sciences. According to the history and background of experimental methods for science and technology dissemination in industrial and above-industrial countries, we have found that the appropriate development and application of basic sciences in engineering and technology have been the reasons for their progress. Relying on the macro and long-term strategic management policies, these countries have been able to monopolize the innovation situation and progress of sustainable development in various aspects of sciences. Therefore, the development of technological system and manufacturing the modern industrial equipment have led to the sustainable development of military power and science in developed countries, and thus they have continued the dissemination of innovation culture and achieving the theorization skill in sciences as well as identifying different ways of new knowledge-based management under such these circumstances. Therefore, they lead the global sustainable development culture and system at different levels towards their demands for further progress. Each of these levels has very appropriate opportunities for development of sciences and technology and needs the support of knowledge production centers and their application in the industry. This point is among the cases with no appropriate and full culture creation in semi-industrial countries. The developing countries have a lot of future-research and idea-building human capital, and thus we will have the innovative 
scientific ideas in innovation development and knowledge production by culture creation and new knowledge-based management in the field of technology and innovation in the case that they are applied and empowered. Therefore, we summarize the important points in developing the management strategies for guiding and promoting the level of knowledge in innovation and technology as follows:

- Providing the national model of new strategies in sustainable development of technology and innovation;

- Developing the theorization view and investigating the simple and short-term ways of innovation in industries;

- Publicizing the scientific information at different levels of population according to their degrees of scientific knowledge;

- Developing the future-study infrastructures through the knowledge-based management;

- Providing the public access to knowledge and familiarity with the new technologies and equipment;

- Developing the activities of trained and professional human resources.

- Expanding and promoting the research in interdisciplinary fields of engineering and basic sciences;

- Creating and developing the public knowledge-based centers for promoting the sciences in non-educational centers of cities;

- Continuous measurement of effects and results of knowledge-based management performance for evaluating the developed strategic policies of technology and innovation in sciences and technology compared to developed and industrial countries [1-3].

\section{Knowledge-Based Management Strategies of Sciences}

The future-study management and planning the science and technology strategies in the country are the tools to achieve the long-term goals of technology and innovation in the industry. In general terms, it is a strategy which utilizes the research, scientific and industrial centers to achieve the new and modern equipment and facilities. It leads the research projects in continuous and permanent way to compete with the leading countries in the industry and modern technologies. The comprehensive management system and applied policies in this process have always been one of the most challenging scientific issues. Therefore, it is essential to review the technology management system in developing countries and accuracy in defined dimensions of sustainable development and macro policies of developed countries in the industry. Three following points should be considered to expand the modern management views:

- Future-study management of new technology ways and modern industrial equipment;

- Strategic management of research and knowledge production [2-3];

- Implementing the internal and external achievements of science and technology in application and industry sectors [4-5];

- Measurement and verification of developing the modern innovation and technology compared to the developed and above-industrial countries

The scientific management of technology and innovation helps to adapt the knowledge resources in designing and manufacturing the modern equipment in various industries and paves the way to reach the high-tech industries and achieve numerous technological opportunities. In this regard, it strengthens the technology and innovation management process by successive assessment in strategic and implementation way, identifying the strengths and weaknesses, and internal and external opportunities and threats in sustainable development. In today's world, when the nations' interaction and objectives of scientific synergy have become the criteria for development, the involvement in the knowledge-based macro policies in engineering and basic sciences in developing and semi-industrial countries is the index of development in scientific management of technology and innovation in modern industry and equipment. Therefore, it is essential to identify and lead the future-study thoughts in researchers and engineers in line with developing the technology and innovation for manufacturing the modern equipment in addition to new strategies of technology management in order to achieve the sustainable scientific and technological development $[5,4]$. Despite the fact that the achievement of knowledge-based management is not the only criterion for transition from the semi-industrial to industrial status, there is a need for the policy of integrated technology strategy as well as the innovator; hence, the following additional points are suggested to know the path of technological innovation and advance of sciences:

- Investigating and identifying the future path and branches of science and technology;

- Moving along the path of modern technologies, assessing and understanding the current potential of domestic technology for its future prosperity;

- We should strengthen the effective technologies in current industries and development and innovation for upcoming years;

- Knowledge-based research and scientific management in identifying the future technologies in sustainable development and industry;

- Identifying the technical experts' scientific abilities outside the country and making the way of future study competitive in engineering and basic sciences with industrialized countries;

- Culture and idea creation and promotion of applied theories in the industry;

- Welcoming and supporting the human capital.

Considering the cases above, the special and long-term policies should be created in integration of management in the country for knowledge-based management along with the development of technology and innovation in the industry; they are summarized as follows: 
- Highlighting and empowering the knowledge-based management capabilities in strategic system of industry and research. [6]

- Changing the direction and leading the innovative and creative research suggestion and projects in line with the ways for expanding the industry and technology directions in the world. [7]

- Establishing the knowledge-based research centers to identify the future technologies and investigating the needs and opportunities of innovation in current equipment and directing the future study of macro policy in line with sustainable scientific and technical development.

Relying on such this management, we provide the strong structure and background in identifying and enabling future researchers and engineers and it has a lot of benefits for advancing the scientific knowledge and innovation in building and designing the modern equipment.

\section{New Technologies Depending on the International Interactions}

The developed and above-industrial countries are the poles and cores of technology and innovation management strategies in the world. In today's global village, the semiindustrial and developing countries need the scientific and technical interactions in engineering and basic sciences with major industrialist in order to achieve the new technology and equipment [8-9]; hence, the policy making and directing the management of sciences should be in a way that the way of transferring the theoretical and applied knowledge is led from the scientific-research centers of developed countries to local universities and industrial units[10-11]. The uniaxial inefficient policy for advancing the knowledge and technology was among the policy makers' fundamental goals in developing countries. Nowadays, the scientific management of growth and innovation in technology is defined through the knowledge synergy and interactions with other countries. Therefore, it is impossible to achieve the modern equipment and movement towards the sustainable scientific, technical and industrial development without taking the advantage of the advanced industrial science and technology which are created and stored in developed countries [12-15]. Therefore, the management strategies which are based on this view, not only lose the ability and power to empower the local knowledge and potential, but also will lose the critical factor in sustainable development namely the period of growth and development in innovation and technology with ascending trend. Thus, as a drop in a raging sea of knowledge and technology, it is appropriate to adopt an appropriate management in knowledge production and acquisition for moving in parallel to the new technology. The effective factors are essential to start a principled, purposeful and comprehensive knowledge and technology namely foresight and understanding the local objectives in promoting the science as well as the innovation needs in modern industries, the way of attracting the foreign knowledge and technologies and a lot of other factors in this regard; hence, it is essential to hold the committees and associations of knowledge production as well as the potential human capital (researchers in various disciplines) in developing countries. It should be noted that the authorities of advanced sciences do not naturally support the $100 \%$ transfer of foreign knowledge and technology; hence, the above-proposed committees should understand the transferred infrastructural sciences and technology at the least time. Otherwise, the industrial and scientific dependence issues will be raised again. According to the above-mentioned issues, it is essential to conduct a comparative study on the management and framework of educational-research programs of engineering and basic sciences in advanced and developing countries. An overview of deficits in research and knowledge-based strategies in semi-industrialized and developing countries for achieving the modern knowledge and technology indicate that the inadequate control and power of theorizing and disseminating the knowledge in engineering and basic sciences along with the lack of international scientific synergy are the main reasons for strategic problems of science and technology and inefficient path of progress and sustainable growth in these countries. Therefore, the background of development in applied sciences of developing countries indicates that the major problem of innovation industry and promotion of science and technology has roots in the type of policy making and scientific management which not only does not follow the rules of interactive system, but also has no significant movement in line with the global macro knowledge-based policies. Therefore, the achievement of appropriate policy and management is among the main objectives of technology management, thus the time and opportunities should be taken to achieve it.

\section{Conclusion}

The knowledge and innovation production in the industry are two important factors which are considered as the powerful weapons in sustainable development. Therefore, the power of countries in political and military international competition directly depends on the development of technology, and manufacturing the modern equipment. Adopting the strategies of technology and innovation development in the industry is a part of requirements and needs of management reformation in developing countries. Finding the way to access to technology and innovation in sciences and technology is a common concern in today's world. Therefore, the convergence and synergy in strategic knowledge management and achievement of modern technology in the industry as an important axis are on the agenda of countries. Nowadays, due to the modern knowledge-based and strategic management policies of sciences, there is a wide acceptance of international cooperation in engineering and basic sciences. In fact, this 
refers to scientific and regional knowledge sharing between developing and developed countries. The process of knowledge management and global macro policies also indicate that the single and central structure has been lessened in the previous technology and innovation of developed countries. Thus, the knowledge-based management is an important axis in leading the technology management in developing and semi-industrial countries in acquiring the new knowledge and achieving the sustainable development and innovation in equipment by utilizing the international transactions of modern sciences. As noted in this article, understanding the strategies for knowledge production, promotion of innovation in industry and movement towards the multi-core international interactions are the bases for the new technology management structure which will strengthen the achievement of sustainable development.

\section{References}

[1] A. Jahanshir, A.H. Jahanshir, "Incorporate New Technologies and Modern Management Approach to the Climate Crisis", National Conference on Modern Disaster Management \& HSE, 25-26 December, Iran, 2013.

[2] R. ADNER, D.A. Levinthal, "The emergence of emerging technologies", California Management Review, vol.45 (1), p.50-66, 2002.

[3] A. WALLERSTEIN, "The modern world system", New York: Academic press, 1974.

[4] S. ZAHRA, A. NIELSEN, "Sources of Capabilities, Integration and Technology Commercialization", strategic Management Journal, 23(5), 377-398, 2002.

[5] G. MARKMAN, D.SIEGEL, et al., "Research and Technology Commercialization", Journal of Management Studies, 45(8), 1401-1423, 2008.
[6] R.E. Evenson, E. Larry, Westphal, "Technological Change and Technology Strategy", Handbook of Development Economics: Volume 3A, (Amsterdam: North-Holland), 1995.

[7] W. M. Cohen, D. A. Levinthal, "Absorptive Capacity: A New Perspective on Quarterly”, vol.35 (1), p. 128-152, 1990.

[8] H.W. Chesbrough, "Open Learning and Innovation, Administrative Science Innovation: the New Imperative for Creating and Profiting from Technology", Harvard business School Press, 2003.

[9] B. Quelin, "Core Competencies R\&D Management and Partnerships", European Management Journal, vol. 18 (5), p. 476-487, 2000.

[10] V. KUMAR, P. JAIN, "Commercialization of New technologies in India: an Empirical Study of Perceptions of Technology Institutions", Expert Systems with Applications, vol. 26 (2), 279-284, 2004.

[11] J. FANG, H. HUETE-PEREZ, et al., "Global coherence of technology: meeting the needs of developing countries", International Journal of technology management, vol. 22 (7/8), 2001.

[12] Y. SO, H. TAE, "Structural Equation Model for Predicting Technology Commercialization Success Index (TCSI)", Technological Forecasting and Social Change Technovation Journal, vol. 70 (9), 1885-899, 2003.

[13] A.N. AFUAH, J.M. Utterback, "Responding to structural industry changes: A technological evolution perspective", Industrial and Corporate Change, vol. 6 (1), p.183-202, 1997.

[14] V.CHIESA, R.Manzini, "Towards a framework for dynamic technology strategy", Technology Analysis and Strategic Management. vol.10 (1), p.111-129, 1998.

[15] M. Sean, Dougherty, "The Role of Foreign Technology in Improving Chinese Productivity", MIT Science and Technology Initiative, Beijing, manuscript, 1997. 